\title{
Natural History Observations of the Scaly Gecko, Hemidactylus scabriceps (Annandale 1906), in India
}

\author{
M. Rameshwaran ${ }^{1}$, Ahamed M. Jerith ${ }^{2}$, and S.R. Ganesh ${ }^{3}$ \\ ${ }^{1}$ Reptile Conservation of India (RCI), No: 9/98, Dr. Chelladurai Nagar, Krishnapuram Post, Tirunelveli-627 011, Tamil Nadu, India \\ ${ }^{2}$ B.Sc. Zoology, The American College, Goripalayam, Madurai-625 002, Tamil Nadu, India \\ ${ }^{3}$ Chennai Snake Park, Rajbhavan Post, Chennai-600 022, Tamil Nadu, India (snakeranglerr@gmail.com)
}

Photographs by the senior author.

$\mathrm{T}$ he Scaly Gecko (Hemidactylus scabriceps) is a rare and elusive terrestrial nocturnal gecko distributed in southeastern India and northern Sri Lanka (Smith 1935; Murthy 1985). Until recently, almost nothing was known about this species (e.g., Wickramasinghe and Somaweera 2008; Somaweera and Somaweera 2009), until a series of findings were published, including its rediscovery (Ganesh and Chandramouli 2010), range extensions and expanded descriptions (Ganesh et al. 2017), and molecular affinities (Srikanthan et al. 2018). Herein, we present the first observations of ovipositioning, hatchlings, and predation in Nagalapuram, Vilathikulam Thaluk, Thoothukudi District, Tamil Nadu, India $\left(9.230^{\circ} \mathrm{N}, 78.120^{\circ} \mathrm{E}\right.$; elev. $40 \mathrm{~m}$ asl).

At 2200 h on 19 April 2018, we observed a gravid female Scaly Gecko (SVL $44 \mathrm{~mm}$, tail length $44 \mathrm{~mm}, 2.86$ g) scratching the ground, apparently searching for a suitable oviposition site. We gently captured the gecko, housed it in an appropriate enclosure $(30 \times 15 \times 7 \mathrm{~cm}$, with $5 \mathrm{~cm}$ of soil and leaf-litter substrate), and monitored it daily. On the very next day, at $2310 \mathrm{~h}$ on 20 April, it dug a hole about $1 \mathrm{~cm}$ deep, laid two eggs (Fig. 1), and covered them with soil and debris, such that the area was indistinguishable from its surroundings. After oviposition the gecko weighed $2.18 \mathrm{~g}$. We then released the female at the exact site of capture. The eggs were white and slightly ovoid, each measuring $8 \times 9.5 \mathrm{~mm}$ and weighing $0.30 \mathrm{~g}$ on the day they were laid. The enclosure was maintained at an ambient air temperature of $30-31^{\circ} \mathrm{C}$ and a relative humidity of 66-68\%.

Both eggs hatched between 2200 and 2400 h on 7 and 8 June 2018 after about 481/2 days of incubation. The hatchlings (Fig. 2) were perfect replicas of adult conspecifics weighing $0.17 \mathrm{~g}$ and measuring about $38 \mathrm{~mm}$ total length (SVL 18 $\mathrm{mm}$, tail length $20 \mathrm{~mm}$, midbody width $3.0 \mathrm{~mm}$, head length
$6 \mathrm{~mm}$, head width $3.5 \mathrm{~mm}$, head depth $3 \mathrm{~mm}$ ). On the second day after hatching, the hatchlings each ate three termites

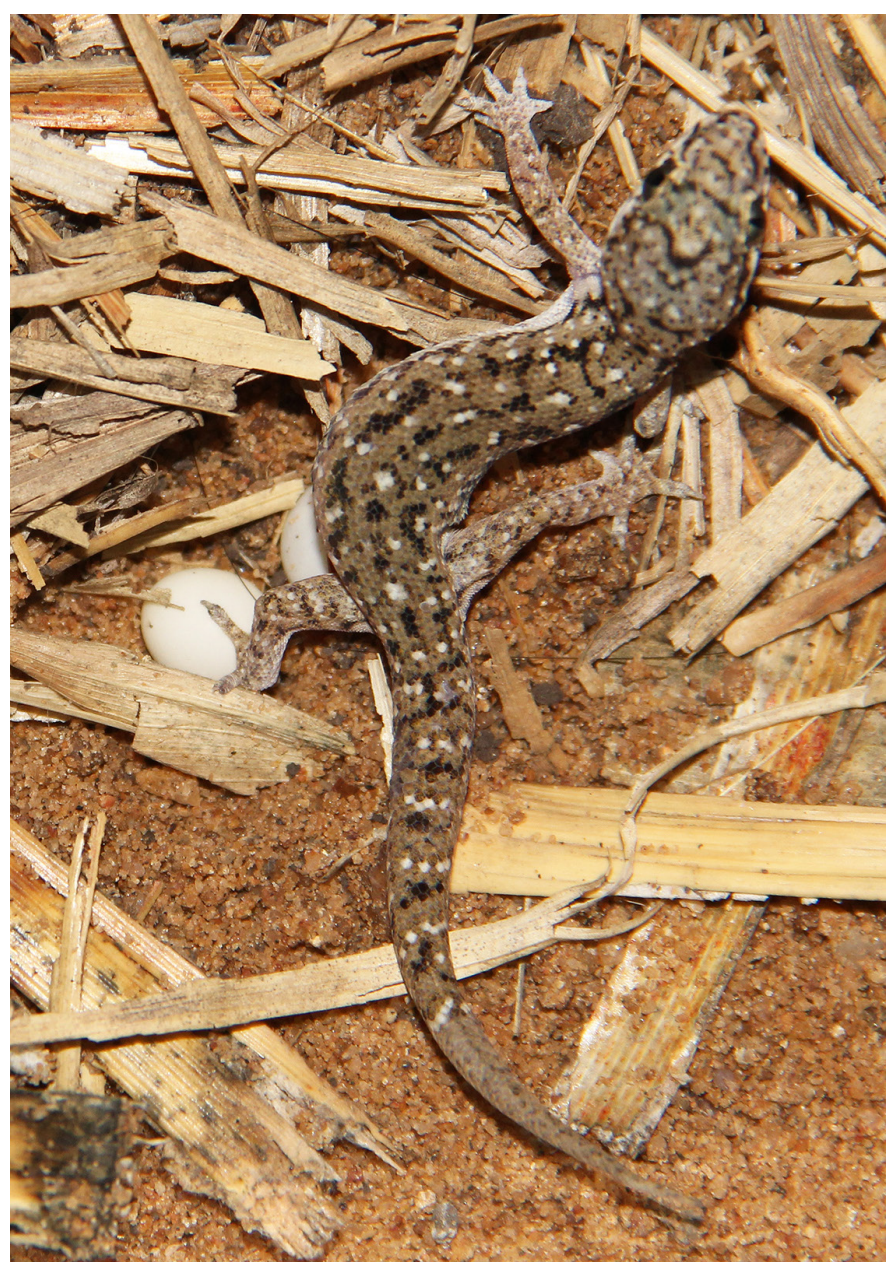

Fig. 1. A female Scaly Gecko (Hemidactylus scabriceps) depositing two eggs in a hole about $1 \mathrm{~cm}$ deep. It subsequently covered the eggs with soil and debris. 

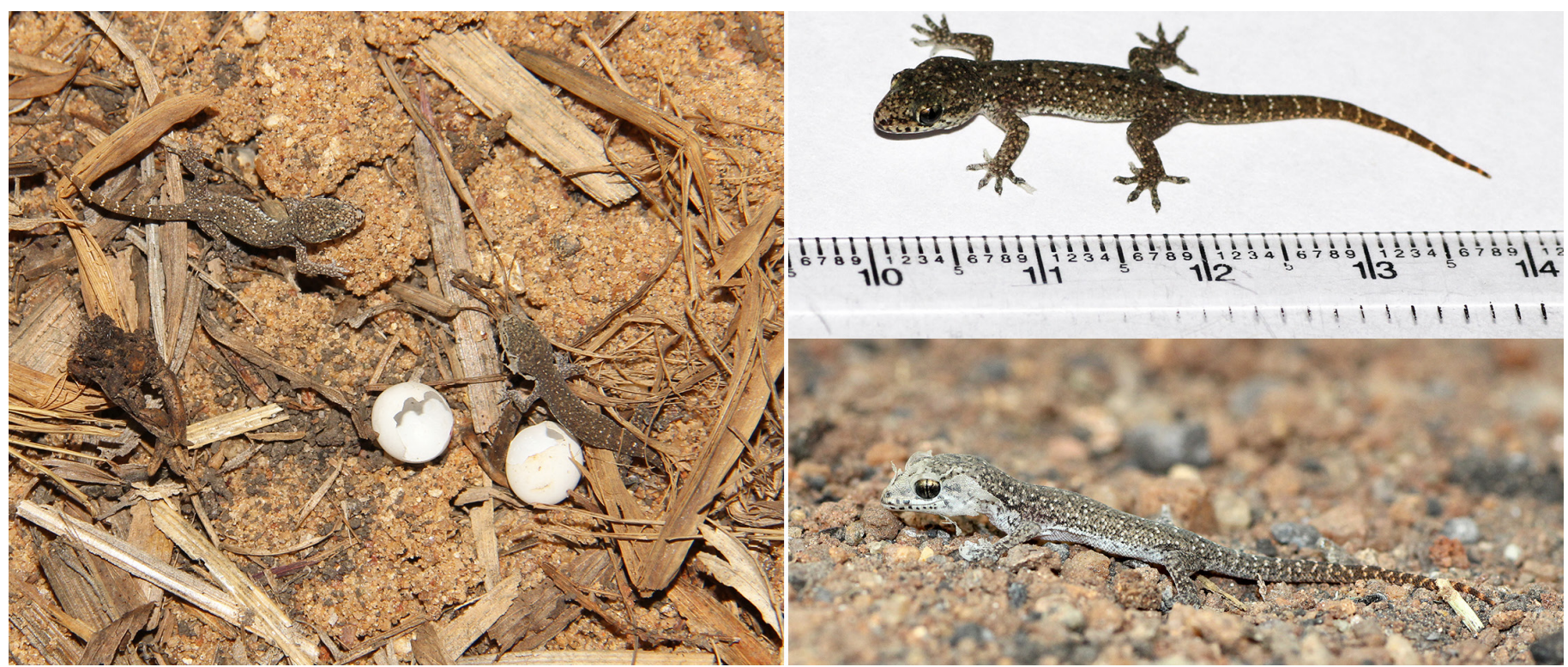

Fig. 2. Hatchling Scaly Geckos (Hemidactylus scabriceps) shortly after emerging from the eggs (left), with scale (top right), and shedding (lower right).

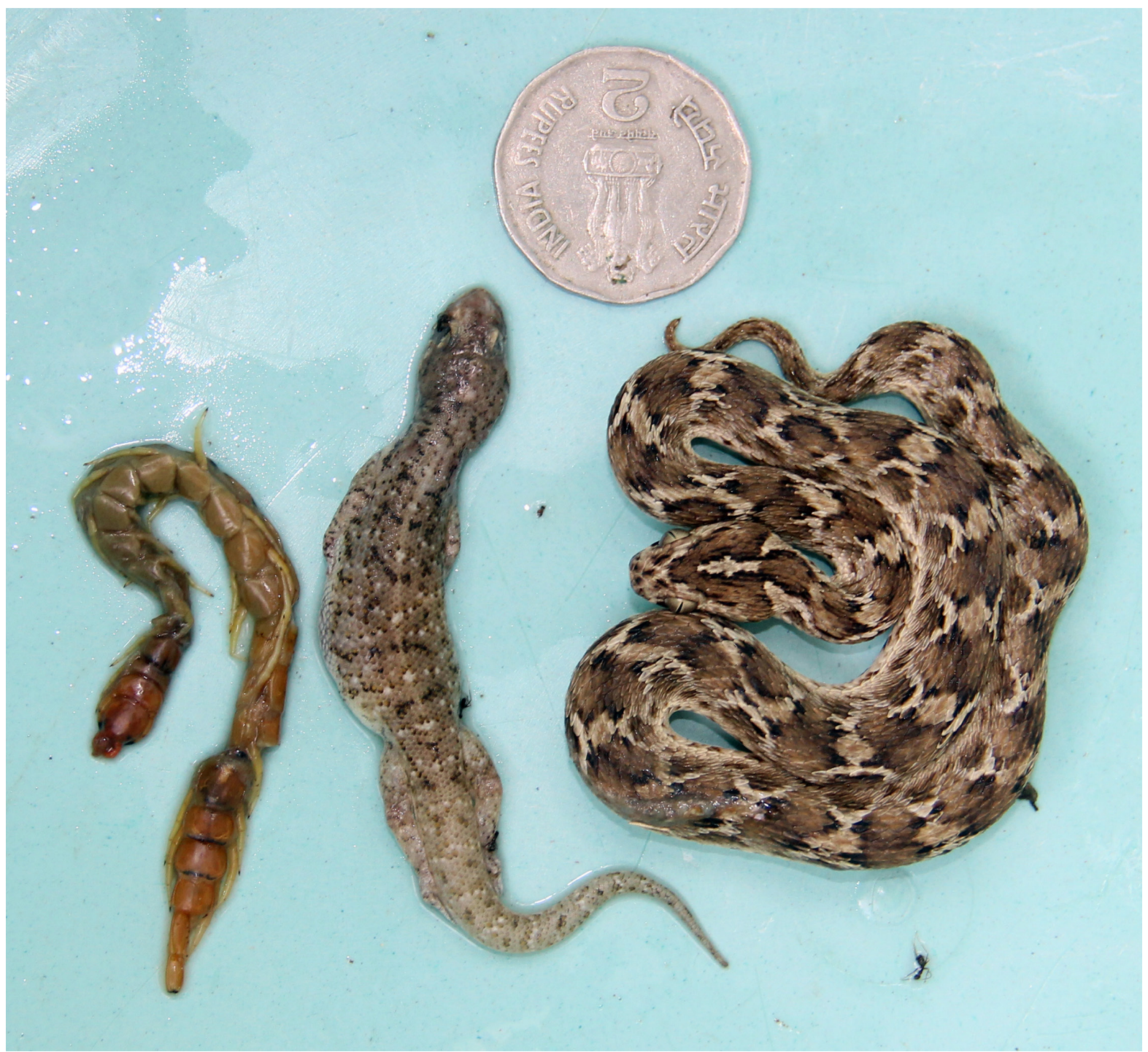

Fig. 3. An adult Indian Saw-scaled Viper (Echis carinatus) with a regurgitated adult centipede and a gravid Scaly Gecko (Hemidactylus scabriceps). 
and began to shed their skins. The following morning, soon after the shedding, we released both hatchlings at the same site where the gravid female was found.

Noteworthy of mention is that the nesting behavior (a hole in the ground) was unlike that of any sympatric congener (Mahendra 1936). Instead, it was more similar to that of agamid lizards (e.g., Calotes spp.) in that the eggs were laid concealed under the soil surface, rather than visibly on the substrate. Among house geckos, a similar but above-ground mound nest some $2 \mathrm{~cm}$ in height was documented for the Mediterranean Gecko (Hemidactylus turcicus) in the USA (Rose and Barbour 1968).

Although predation on Scaly Geckos has not been recorded previously, both adults and hatchlings presumably are vulnerable to a wide variety of predators. At $0258 \mathrm{~h}$ on 12 April 2018, we observed an adult Indian Saw-scaled Viper (Echis carinatus) with a bulge indicative of a recent feeding event. Within a few minutes, the viper regurgitated an adult centipede (species not identified) and a gravid H. scabriceps (Fig. 3). The Scaly Gecko was one-third the length of the snake.

\section{Literature Cited}

Ganesh, S.R. and S.R. Chandramouli 2010. Rediscovery of Hemidactylus scabriceps (Annandale, 1906) (Reptilia: Sauria: Gekkonidae) from Eastern Tamil Nadu, India. Russian Journal of Herpetology 17: 70-74.

Ganesh, S.R., M. Rameshwaran, A.J. Naveen, and M.J. Ahamed. 2017. On two little-known terrestrial South Asian geckoes Hemidactylus reticulatus and Hemidactylus scabriceps (Reptilia: Gekkonidae). Journal of Threatened Taxa 9: 10171-10177.

Mahendra, B.C. 1936. Contributions to the bionomics, anatomy, reproduction and development of the Indian house-gecko, Hemidactylus flaviviridis Rüppel. Part I. Proceedings of the Indian Academy of Sciences-Section B 4: 250-281.

Murthy, T.S.N. 1985. A field guide to the lizards of Western Ghats. Records of the Zoological Survey of India Occasional Paper 72: 1-51.

Rose, F.L. and C.D. Barbour. 1968. Ecology and reproductive cycles of the introduced gecko, Hemidactylus turcicus, in the southern United States. American Midland Naturalist 79: 159-168.

Smith, M.A. 1935. The fauna of British India, including Ceylon and Burma. Reptilia and Amphibia. Vol. II.-Sauria. Taylor and Francis, London, UK.

Somaweera, R. and N. Somaweera. 2009. Lizards of Sri Lanka: A Colour Guide with Field Keys. Edition Chimaira, Frankfurt am Main, Germany.

Srikanthan, A.N., C.K. Gandla C.K., Aishwarya J. Urs, and S.R. Ganesh. 2018. Appearances are deceptive: molecular phylogeny recovers the Scaly Gecko Hemidactylus scabriceps (Reptilia: Squamata: Gekkonidae) as a member of a scansorial and rupicolous clade. Journal of Threatened Taxa 10: 12147-12162.

Wickramasinghe, M. and R. Somaweera. 2008. Changes in the distribution ranges of the Sri Lankan Hemidactylus species. Gekko 5(2): 44-60. 